\title{
Propeller-like Conformation of Diphenylacetic Acid
}

\author{
Manuela Ramos Silva Claudia Cardoso • \\ Ana Matos Beja · Jose A. Paixão · Sergio R. Domingos
}

Received: 3 October 2007/ Accepted: 19 November 2007/Published online: 4 December 2007

(C) Springer Science+Business Media, LLC 2007

\begin{abstract}
Crystal structure of diphenylacetic acid has been solved by X-ray diffraction. The crystals are monoclinic, space group $\mathrm{P} 21 \mathrm{c}$, with $a=12.254(4) \AA, b=7.2260(8) \AA$, $c=17.521(4) \AA, \quad \beta=133.38(1)^{\circ}, \quad \mathrm{Mr}=212.24, \quad \mathrm{~V}=$ 1127.6(5) $\AA^{3}, Z=4$ and $R=0.045$. A strong hydrogen bond links the molecules in dimers. The dimers are connected by weaker $\mathrm{C}-\mathrm{H} \cdots \pi$ and $\pi \cdots \pi$ interactions. A calculation was performed for the isolated molecule and for the dimer within the Hartree-Fock (HF) level with a 6$311 \mathrm{G}(\mathrm{d})$ basis set. In both calculations, the minimum of the energy is achieved with the phenyl rings assuming a more symmetric arrangement around the central carboxylic plane than is experimentally observed.
\end{abstract}

Keywords Diphenylacetic acid · Liquid crystal · Crystal structure - Hydrogen bonds .

Hartree-Fock calculation

\section{Introduction}

Liquid crystals are substances that exhibit a phase of matter with properties between those of a conventional liquid, and those of a solid crystal. Many substances are liquid

Electronic supplementary material The online version of this article (doi:10.1007/s10870-007-9311-9) contains supplementary material, which is available to authorized users.

M. R. Silva ( $₫)$ · A. M. Beja · J. A. Paixão · S. R. Domingos CEMDRX Physics Department, University of Coimbra, Rua Larga, Coimbra 3004-516, Portugal

e-mail: manuela@pollux.fis.uc.pt

C. Cardoso

CFC, Physics Department, University of Coimbra, Coimbra 3004-516, Portugal crystals, some of them as common as soap, and in most of them the liquid crystalline structure consists of a strip-like or disc-like core in the centre and long alkyl chains in the outer region. A few are of the flying-seed-like type. Ohta et al. have shown that sodium diphenylacetate is one of this rare liquid crystals showing a hexagonal columnar mesophase [1]. The arrangement of the molecules in the liquid crystal phase correlates with and resembles that observed in the solid state, according to our study [2]. In the crystal structure of sodium diphenylacetate, each $\mathrm{Na}^{+}$ion is coordinated by four carboxylate $\mathrm{O}$ atoms at distances in the range 2.207 (2)-2.467 (3) $\AA$ to form cubes of $\mathrm{Na}$ and $\mathrm{O}$ atoms which are linked via the carboxylate $\mathrm{C}$ atoms into a columnar structure. The two phenyl groups are in the outside of the columns and are oriented like the blades of a propeller. Preliminary results on potassium diphenylacetate show the same formation of columns while the rubidium diphenylacetate crystal structure has less symmetry giving rise to the formation of ladders instead of columns [3].

Within our project of studying diphenylacetate complexes, we have undertaken the study of pure crystalline diphenylacetic acid. A search on the CSD database showed that the diphenylacetic acid atomic coordinates were unavailable. Minimum crystal data have been published by Koshima et al. [4].

The molecule of diphenylacetic acid has the ability of promoting absolute asymmetric synthesis, that is to assist the formation of enantiomerically enriched products from achiral precursors without the intervention of chiral chemical reagents or catalysts. Diphenylacetic acid has been used to cocrystallize with acridines originating chiral crystals $[4,5]$. It is the propeller like arrangement of the phenyl rings in the diphenylacetic acid molecule that causes a chiral conformation in an otherwise achiral molecule. 
To investigate the effect of the intermolecular interactions in the conformation of the molecule we have performed an optimization of the geometry of the isolated molecules and of the strongly H-bonded dimer by ab-initio Hartree-Fock calculations.

\section{Experimental and Computational Methods}

Preparation of Diphenylacetic Acid

Single crystals of the title compound were collected directly from the flask purchased from Sigma-Aldrich (99\%).

\section{Crystal Structure Determination}

A crystal of the title compound having approximate dimensions of $0.49 \mathrm{~mm} \times 0.24 \mathrm{~mm} \times 0.22 \mathrm{~mm}$ was glued on a glass fiber and mounted on a Bruker Apex II difractometer. Diffraction data were collected at room temperature 293(2) $\mathrm{K}$ using graphite monochromated Mo $\mathrm{K} \alpha(\lambda=0.71073 \AA)$. The crystallographic structure was solved by direct methods (SHELXS-97) [6]. Refinements were carried out with SHELXL-97 [6] package. All refinements were made by full-matrix least-squares on $\mathrm{F}$ [2], with anisotropic displacement parameters for all nonhydrogen atoms. Hydrogen atoms were included in the refinement in calculated positions. Exception made to the carboxylic $\mathrm{H}$ atom whose coordinates were allowed to refine and $\mathrm{U}_{\text {iso }}(\mathrm{H})=1.2 \mathrm{U}_{\text {eq }}(\mathrm{O})$. The final least-squares cycle was based on 2,296 observed reflections $[I>2 \sigma(I)]$ and 145 variable parameters, converged with $R=0.0451$ and $w R=0.1271$. Additional information to the structure determinations is given in Table 1. Hydrogen bond geometric data is given on Table 2. Selected bond distances and angles can be seen in Table 3. Supplementary data have been deposited at the Cambridge Crystallographic Data Centre (CCDC No. 652158).

\section{Calculations}

The structure optimization calculations of the isolated molecule and of the dimer were performed using the code GAMESS [7] within the Hartree-Fock approximation with a 6-311G(d) basis sets [8-11]. The calculation was relaxed from the X-ray geometry. At the final equilibrium geometry the maximum gradient was $10^{-5}$ Hartree $\mathrm{Bohr}^{-1}$. The molecules of the dimer were related by an imposed inversion centre.
Table 1 Crystal data and structure refinement the title compound

\begin{tabular}{ll}
\hline Empirical formula & $\mathrm{C}_{14} \mathrm{H}_{12} \mathrm{O}_{2}$ \\
Formula weight & 212.24 \\
Temperature $(\mathrm{K})$ & $293(2)$ \\
Wavelength $(\AA)$ & 0.71073 \\
Crystal system & Monoclinic \\
Space group & $\mathrm{P} 2{ }_{1} / \mathrm{c}$ \\
$a(\AA)$ & $12.254(4)$ \\
$b(\AA)$ & $7.2260(8)$ \\
$c\left(^{\AA}\right)$ & $17.521(4)$ \\
$\alpha\left(^{\circ}\right)$ & 90 \\
$\beta\left(^{\circ}\right)$ & $133.38(1)$ \\
$\gamma\left({ }^{\circ}\right)$ & 90 \\
Volume $\left(\AA^{3}\right)$ & $1127.6(5)$ \\
$Z$ & 4 \\
Calculated density $\left(\mathrm{g} / \mathrm{cm}^{3}\right)$ & 1.250 \\
Absorption coefficient $\left(\mathrm{cm}^{-1}\right)$ & 0.083 \\
$F(000)$ & 448 \\
Crystal size (mm) & $0.49 \times 0.24 \times 0.22$ \\
$\theta$ range for data collection $\left({ }^{\circ}\right)$ & $2.29-30.89$ \\
Index ranges & $-16<\mathrm{h}<17,-10<\mathrm{k}<10$, \\
& $-25<1<25$ \\
Reflections collected/unique & $32,797 / 3,483[R($ int $)=0.0282]$ \\
Completeness to $\theta=30.89$ & $97.6 \%$ \\
Refinement method & Full-matrix least-squares on $F^{2}$ \\
Data/restraints/parameters & $2296 / 0 / 145$ \\
Goodness-of-fit on $F^{2}$ & 1.071 \\
Final $R$ indices $[I>2 \sigma(I)]$ & $R_{1}=0.0451 w R_{2}=0.1102$ \\
$R$ indices (all data) & $R_{1}=0.0772 w R_{2}=0.1271$ \\
Largest diff. peak and hole $\left(\mathrm{e} \AA^{-3}\right)$ & 0.250 and -0.176 \\
\hline &
\end{tabular}

\section{Results and Discussion}

Crystal Structure of the Title Compound

The structure of the title compound together with the atomnumbering scheme, is illustrated in Fig. 1. The packing diagram is shown in Fig. 2. Geometric details of the intermolecular interactions are listed on Tables 2-3. Selected bond lengths and angles are listed in Table 4.

The title compound, diphenylacetic acid (Fig. 1), crystallizes in a centrosymmetric space group $\mathrm{P} 2_{1} / \mathrm{c}$ with the acid molecules assembled in dimers via strong hydrogen bonds between the carboxylic groups. The donor-acceptor distance is $2.660(2) \AA$ with the bond angle $175(3)^{\circ}$. The conformation of the phenyl rings is like the blades of a propeller making $\mathrm{C} 2$ a chiral centre. An inversion centre relates the two dimers thus making the whole structure achiral. Besides the strong hydrogen bond, other intermolecular interactions play a role in governing the crystal packing: $\mathrm{C}-\mathrm{H} \cdots \pi$ and $\pi \cdots \pi$ interactions. 
Table 2 Intermolecular H-bond geometry $\left(\AA,^{\circ}\right)$

\begin{tabular}{lllll}
\hline & D-H & H $\cdots A$ & D $\cdots A$ & D-H $\cdots A$ \\
\hline $\mathrm{O} 2-\mathrm{H} 21 \ldots \mathrm{O} 1^{\mathrm{i}}$ & $0.94(2)$ & $1.73(2)$ & $2.660(2)$ & $175(3)$ \\
\hline
\end{tabular}

(Symmetry code $i:-1-x,-y,-1-z$ )

Table $3 \mathrm{C}-\mathrm{H} \cdots \pi$ interactions geometry $\left(\AA{ }^{\circ}{ }^{\circ}\right)$

\begin{tabular}{llllll}
\hline & $\mathrm{d}_{\mathrm{H} \cdots \pi}$ & $\theta$ & $\alpha$ & $\mathrm{d}=\mathrm{d}_{\mathrm{H} \cdots \pi} \cos \theta$ & \\
\hline $\mathrm{C} 2-\mathrm{H} 2 \cdots \mathrm{Cg} 1^{\mathrm{ii}}$ & 3.053 & 65.3 & 171.7 & 1.278 & Type II \\
$\mathrm{C} 7-\mathrm{H} 7 \cdots \mathrm{Cg} 2^{\mathrm{iii}}$ & 3.325 & 74.6 & 126.5 & 0.881 & Type III \\
$\mathrm{C} 8-\mathrm{H} 8 \cdots \mathrm{Cg} 2^{\mathrm{iii}}$ & 3.265 & 60.8 & 129.4 & 1.592 & Type V \\
$\mathrm{C} 12-\mathrm{H} 12 \cdots \mathrm{Cg} 2^{\text {iv }}$ & 3.099 & 85.7 & 146.5 & 0.233 & Type III \\
\hline
\end{tabular}

(Symmetry codes ii: $-x,-1 / 2+y,-1 / 2-z$, iii: $x, 1+y, z$ iv: $-1-x,-1 / 2+y,-1 / 2-z ; \mathrm{Cg} 1$-centroid of ring $\mathrm{C} 3-\mathrm{C} 8, \mathrm{Cg} 2-$ centroid of ring C9-C14, definition of geometric parameters according to [12])

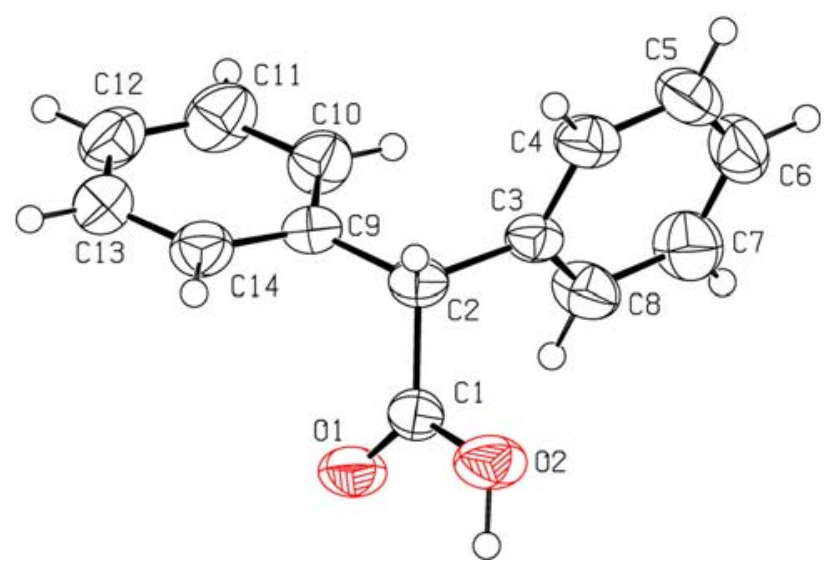

Fig. 1 ORTEP diagram of the title compound with the ellipsoids drawn at the $50 \%$ probability level, with the atomic labelling scheme

There are four $\mathrm{C}-\mathrm{H} \cdots \pi$ intermolecular interactions, involving four hydrogen atoms and the $\pi$ electron system of the two rings (Table 3). In two of the bonds, the hydrogen atom is directly above the centre of the ring but the $\mathrm{C}-\mathrm{H}$ bond points towards a ring carbon. This geometry corresponds to a type III interaction as classified by Malone et al. [12]. In another bond $(\mathrm{C} 2-\mathrm{H} 2 \cdots \pi)$, the classical T-shape geometry is almost accomplished, but a slight deviation of the $\mathrm{H}$ atom from the centre of the ring makes it more of the type II. In the remaining bond $(\mathrm{C} 8-\mathrm{H} 8 \cdots \pi)$ the hydrogen atom interacts with a carbon at the edge of the

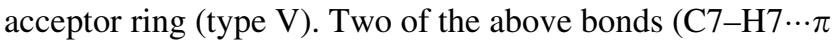
and $\mathrm{C} 8-\mathrm{H} 8 \cdots \pi$ ) share the $\mathrm{H}$ atoms with the same $\pi$ system. The $\mathrm{C}-\mathrm{H} \cdots \pi$ interactions join the molecules in layers parallel to the $a b$ plane (Fig. 2).

The $\pi \cdots \pi$ interaction displays the usual slipped stacking geometry, with the interacting $\pi$ systems parallel displaced.

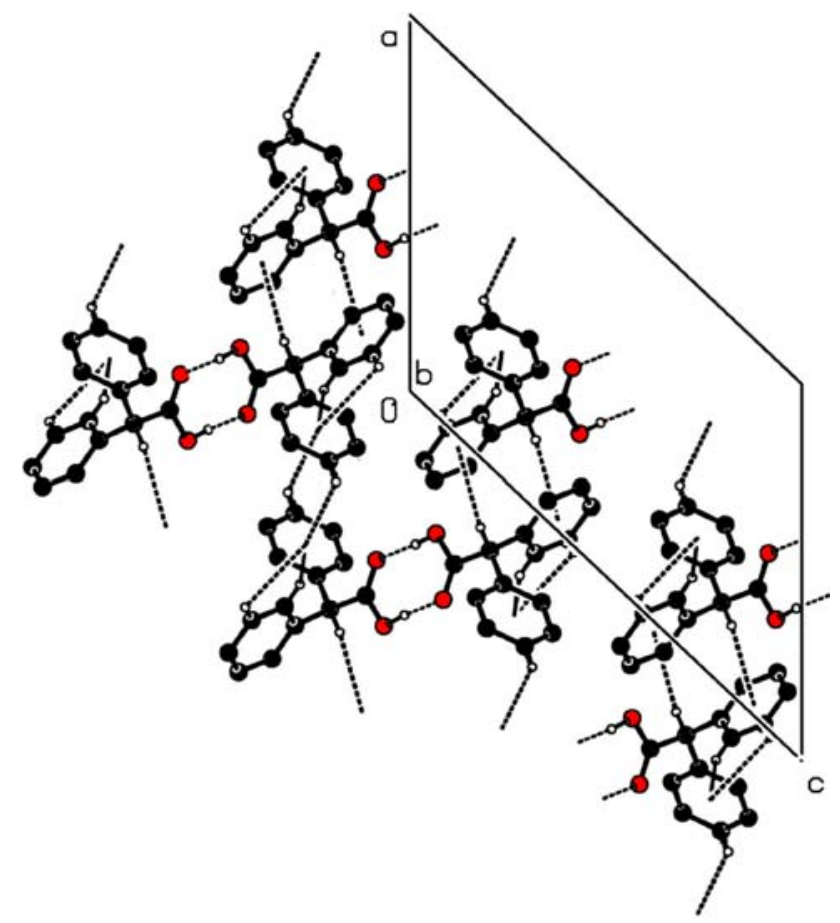

Fig. 2 Partial packing diagram of the title compound with the $\mathrm{H}$ bonds and $\mathrm{C}-\mathrm{H} \cdots \pi$ interactions drawn as dashed lines

Table 4 Selected structural parameters by X-ray and theoretical calculations

\begin{tabular}{lccr}
\hline $\begin{array}{l}\text { Bond distances }(\AA) \\
\text { and angles }\left(^{\circ}\right)\end{array}$ & Experimental & \multicolumn{2}{c}{ Calculated } \\
\cline { 3 - 4 } & & Monomer & \multicolumn{1}{c}{ Dimmer } \\
\hline $\mathrm{C} 1-\mathrm{O} 1$ & $1.215(1)$ & 1.182 & 1.196 \\
$\mathrm{C} 1-\mathrm{O} 2$ & $1.309(1)$ & 1.327 & 1.304 \\
$\mathrm{O} 1-\mathrm{C} 1-\mathrm{O} 2$ & $122.7(1)$ & 122.19 & 123.27 \\
$\mathrm{O} 2-\mathrm{C} 1-\mathrm{C} 2-\mathrm{C} 3$ & $67.1(1)$ & 105.27 & 102.90 \\
$\mathrm{O} 2-\mathrm{C} 1-\mathrm{C} 2-\mathrm{C} 9$ & $-165.3(1)$ & -126.85 & -128.85 \\
$\mathrm{C} 1-\mathrm{C} 2-\mathrm{C} 3-\mathrm{C} 8$ & $40.5(2)$ & 33.74 & 35.20 \\
$\mathrm{C} 1-\mathrm{C} 2-\mathrm{C} 3-\mathrm{C} 14$ & $63.9(1)$ & 105.65 & 106.38 \\
\hline
\end{tabular}

The centroid-centroid distance is 4.867(2) $\AA$ and the angle between the ring normal and the vectors between the ring centroids is $39.9(1)^{\circ}$. The shorter atom-atom contact between the two parallel planes is 3.771(2) $\AA$ (C7 to $\mathrm{C} 7^{i}$. $i:-x,-y,-z)$, characteristic of a weak interaction [13]. The $\pi \cdots \pi$ interactions join the dimers in chains that run along the $c$ axis (Fig. 2).

The geometry optimization for the isolated molecule converges to a molecular conformation more symmetric than the one observed in the solid state (Fig. 3). The calculated parameters show an angle between the leastsquares planes of both phenyl rings of $74.1^{\circ}$. The angle between the mean plane of phenyl ring $\mathrm{A}(\mathrm{C} 3-\mathrm{C} 8)$ and the carboxylic mean plane is $64.4^{\circ}$. The angle between the 


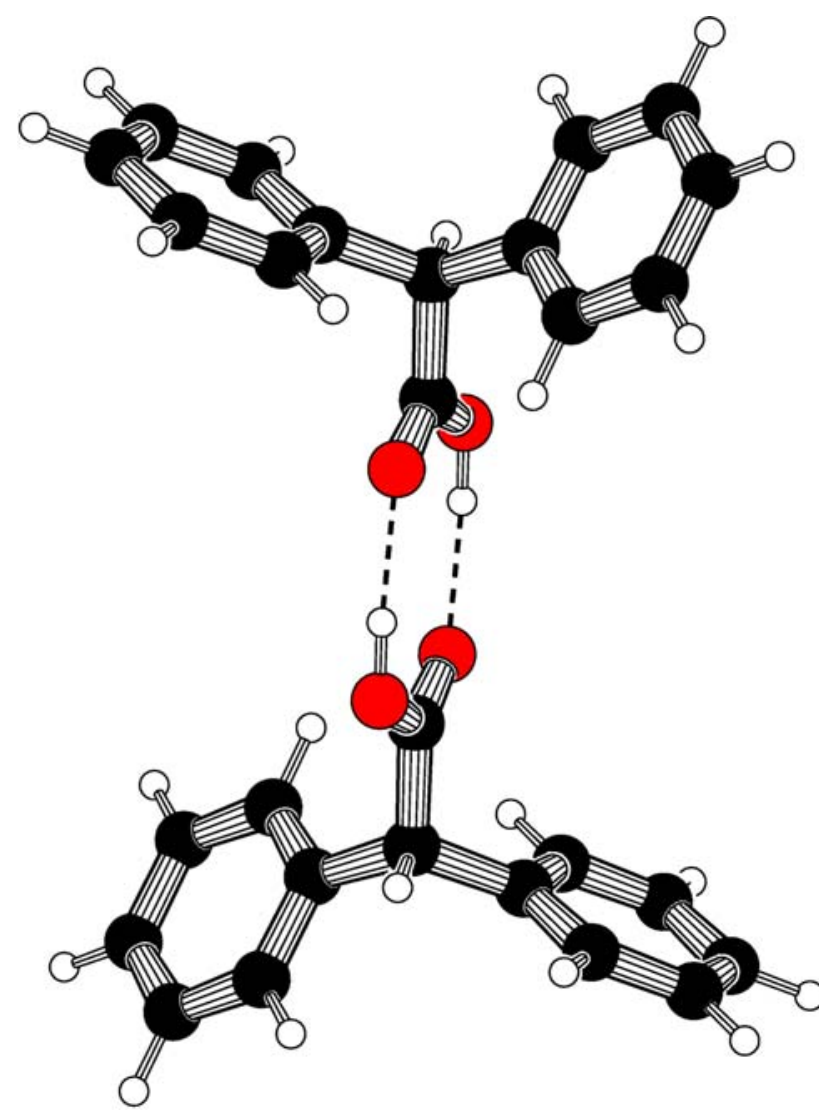

Fig. 3 The molecular conformation of the dimer as resulted from the Hartree-Fock calculations

mean plane of phenyl ring B (C9-C14) and the carboxylic mean plane is $64.2^{\circ}$. There is a strong asymmetry between the $\mathrm{C}-\mathrm{O}$ bond lengths (see Table 3 ).

The geometry optimization for the dimer converges to a less symmetric molecular conformation. The strong hydrogen bond observed in the solid state is maintained. The asymmetry between the $\mathrm{C}-\mathrm{O}$ bond lengths diminishes since the $\mathrm{H}$ atom is shared between $\mathrm{O} 2$ and $\mathrm{O} 1$ of inversion related molecules. The calculated parameters show an angle between the least-squares plane of both phenyl rings of $72.8^{\circ}$. The angle between the mean plane of phenyl ring $\mathrm{A}$ and the carboxylic mean plane is $66.3^{\circ}$. The angle between the mean plane of phenyl ring $\mathrm{B}$ and the carboxylic mean plane is $63.5^{\circ}$.

In the solid state the intermolecular interactions distort even more the symmetry of the isolated monomer. There is a great involvement of the rings in intermolecular interactions both as donors and acceptors and different conformations may be favoured energetically. The energy of a mole of dimers is $-861984 \mathrm{kcal} / \mathrm{mol}$ for the observed conformation and $-862255 \mathrm{kcal} / \mathrm{mol}$ for the optimized geometry, which indicates the role of the packing forces in the cohesion of the crystal. The angle between the leastsquares planes of the phenyl rings is $83.99(9)^{\circ}$. The angle between the mean plane of phenyl ring $\mathrm{A}$ and the carboxylic mean plane is $86.81(8)^{\circ}$. The angle between the mean plane of phenyl ring $\mathrm{B}$ and the carboxylic mean plane is $70.03(8)^{\circ}$.

The HOMA parameter [14] describing aromaticity, which has a value of 1.000 for benzene, is equal to 0.961 (for ring A) and 0.982 (for ring B). In both calculations the converged geometry results in equal HOMA parameters for the phenyl rings [0.996 for the dimer and 0.997 for the monomer].

\section{Supplementary Material}

Crystallographic data for structural analysis have been deposited with the Cambridge Crystallographic Data Center, CCDC 652158. Copies of this information may be obtained free of charge on application to CCDC, 12 Union Road, Cambridge CB2 1EZ, UK (fax: +44 1223336 033; e-mail: deposit@ccdc.cam.ac.uk or http://www.ccdc.cam. ac.uk).

Acknowledgement This work was supported by Fundação para a Ciência e a Tecnologia under project POCI/FIS/57876/2004.

\section{References}

1. Ohta K, Shibuya T, Ando M (2006) J Mater Chem 16:3635

2. Paixão JA, Nascimento FV, Matos Beja A, Ramos Silva M (2000) Acta Cryst C56:168

3. Ramos Silva M, Matos Beja A, Paixão JA, Domingos SR, Martín-Gil JJ (2007) Chem Cryst 37:49

4. Koshima H, Ding K, Chisaka Y, Matsuura T (1996) J Am Chem Soc 118:12059

5. Koshima H (2005) Mol Cryst Liq Cryst 440:207

6. Sheldrick GM (1997) SHELXS97 and SHELXL-97. Univserity of Gottingen, Germany

7. Schmidt MW, Baldridge KK, Boatz JA, Elbert ST, Gordon MS, Jensen J, Koseki S, Matsunaga N, Nguyen KA, Su S, Windus TL, Dupuis M, Montgomery JA (1993) J Comput Chem 14:1347

8. Ditchfield R, Hehre WJ, Pople JA (1971) J Chem Phys 54:724

9. Hehre WJ, Ditchfield R, Pople JA (1972) J Chem Phys 56:2257

10. Hariharan PC, Pople JA (1973) Theoret Chim Acta 28:213

11. Clark T, Chandrasekhar J, Spitznagel GW, Schleyer P von RJ (1983) Comput Chem 4:294

12. Malone JF, Murray CM, Charlton MH, Docherty R, Lavery AJ (1997) J Chem Soc Faraday Trans 93:3429

13. Janiak CJ (2000) Chem Soc Dalton Trans 3885

14. Krygowski TM (1993) J Chem Inf Comput Sci 33:70 